[2] Reker D, et al. "Sprifermin (rhFGF18) modulates extracellular matrix turnover in cartilage explants ex vivo." J Transl Med. 2017;15.

[3] Hochberg MC, et al. "Effect of Intra-Articular Sprifermin vs Placebo on Femorotibial Joint Cartilage Thickness in Patients With Osteoarthritis". JAMA. 2019; Oct 8;322(14)

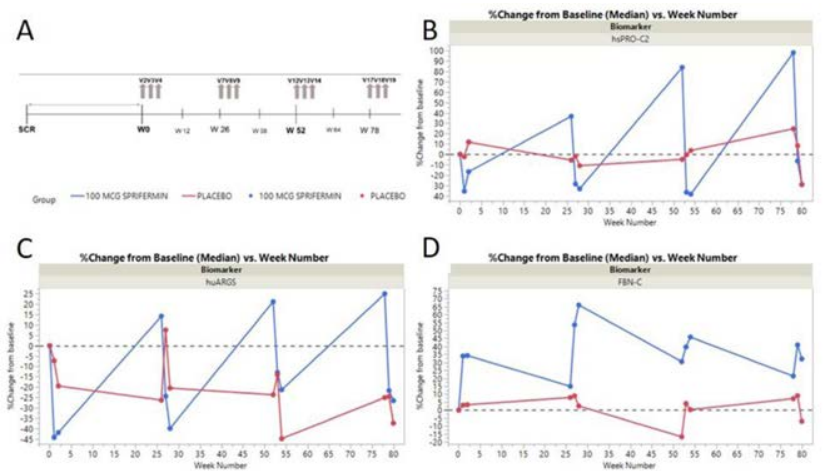

Fig. Assessment of cartilage markers in synovial fluid at the 4 cycles. A) Study overview. B) type ॥ collagen formation, PRO-C2. C) Aggrecan degradation, huARGS. D) Fibronectin degradation, FBN-C. Data are shown as median of available samples at each timepoint.

Disclosure of Interests: Anne-Christine Bay-Jensen Shareholder of: Nordic Bioscience A/S, Employee of: Full time employee at Nordic Bioscience A/S., Angela Manginelli Employee of: Merck KGaA, Flavie Moreau Employee of: Merck KGaA, Yi He Employee of: $\mathrm{YH}$ is a full time employee of Nordic Bioscience A/S, Yunyun Luo Employee of: Nordic Bioscience A/S, Jeppe Ragnar Andersen Shareholder of: Nordic Bioscience A/S., Employee of: Full time employee of Nordic Bioscience., Asger Reinstrup Bihlet Shareholder of: Nordic Bioscience A/S., Morten Karsdal Shareholder of: Nordic Bioscience A/S., Employee of: Full time employee at Nordic Bioscience A/S., Hans Gühring Employee of: Merck KGaA, Christoph Ladel Employee of: Merck KGaA

DOI: 10.1136/annrheumdis-2020-eular.3855

\section{OP0190 UNDERSTANDING CURRENT PRESCRIPTION DRUG TREATMENT PARADIGMS FOR PATIENTS WITH OSTEOARTHRITIS IN EUROPE}

P. G. Conaghan ${ }^{1}$, L. Abraham ${ }^{2}$, P. Graham-Clarke ${ }^{3}$, L. Viktrup ${ }^{4}$, J. C. Cappelleri ${ }^{5}$, C. Beck ${ }^{2}$, A. G. Bushmakin ${ }^{5}$, N. Hatchell ${ }^{6}$, E. Clayton ${ }^{6}$, J. Jackson ${ }^{6} .{ }^{1}$ University of Leeds, Leeds, United Kingdom; ${ }^{2}$ Pfizer Ltd., Surrey, United Kingdom; ${ }^{3} E l i$ Lilly and Co, Sydney, Australia; ${ }^{4}$ Eli Lilly and Co., Indianapolis, United States of America; ${ }^{5}$ Pfizer, Groton, United States of America; ${ }^{6}$ Adelphi Real World, Bollington, United Kingdom

Background: Joint pain is the most prevalent symptom for sufferers of osteoarthritis $(\mathrm{OA})$. Pharmacological management of $O A$ is restricted by limited efficacy and considerable toxicity, with growing fears about opioid use.

Objectives: To understand the current real-world prescribed drug treatment paradigm related to OA disease severity for patients in $5 \mathrm{EU}$ countries; France, Germany, Italy, Spain and the UK.

Methods: Data were drawn from the Adelphi OA Disease Specific Programme (2017-18), a point-in-time study of physicians and their patients. Physicians classified their patients as currently having mild, moderate or severe disease severity, and provided details on currently prescribed OA therapy and physician satisfaction with therapy, rated from very satisfied to very dissatisfied. Patients were excluded from these analyses if they suffered from back and neck OA only, and shoulder OA that had not been diagnosed by X-ray. Comparisons among disease severity groups were made using analysis of variance and chi-squared tests.

Results: The study included 489 physicians (primary care physicians, rheumatologists, orthopaedists) reporting on 3596 of their OA patients: $24 \%$ mild $(n=874), 53 \%$ moderate $(n=1904)$, and $23 \%$ severe $(n=818)$. Overall, $73 \%$ patients were prescribed at least one drug for their OA $(65 \%$ of mild; $76 \%$ of moderate; $77 \%$ of severe patients $[<0.001])$. Paracetamol $(34 \%)$ was the most commonly prescribed OA treatment. NSAIDs $(31 \%)$ and opioids $(27 \%)$ were also frequently prescribed treatments, and worsening severity was associated with an increase in opioid use (11\% of mild; $26 \%$ of moderate, $47 \%$ of severe patients $[<0.001]$ ), but not NSAID (Table 1). The mean number of prescription medications increased ( 0.9 for mild; 1.4 for moderate; 1.6 for severe patients $[<0.001])$ and physician satisfaction with treatment decreased $(86 \%$ for mild; $70 \%$ for moderate; $41 \%$ for severe $[<0.001]$ ) with worsening OA disease severity.
Table 1. Prescribed treatment by physician-reported OA severity

\begin{tabular}{lccc}
\hline & $\begin{array}{c}\text { Mild } \\
(\mathrm{n}=874)\end{array}$ & $\begin{array}{c}\text { Moderate } \\
(\mathrm{n}=1904)\end{array}$ & $\begin{array}{c}\text { Severe } \\
(\mathrm{n}=818)\end{array}$ \\
\hline Current class of medication prescribed for OA, $\mathrm{n}(\%)$ & & & \\
Paracetamol & $186(21.3)$ & $663(34.8)$ & $313(38.3)$ \\
NSAIDs & $267(30.5)$ & $605(31.8)$ & $237(29.0)$ \\
Any opioid & $93(10.6)$ & $501(26.3)$ & $386(47.2)$ \\
Weak opioid & $82(9.4)$ & $407(21.4)$ & $255(31.2)$ \\
Strong opioid & $11(1.3)$ & $99(5.2)$ & $146(17.8)$ \\
Opioid + analgesic (combined) & $6(0.7)$ & $15(0.8)$ & $7(0.9)$ \\
Corticosteroid & $31(3.5)$ & $150(7.9)$ & $92(11.2)$ \\
Glycosaminoglycan & $50(5.7)$ & $149(7.8)$ & $62(7.6)$ \\
Viscosupplement & $12(1.4)$ & $93(4.9)$ & $42(5.1)$ \\
Number of currently prescribed drug classes, mean (SD) & $0.9(0.8)$ & $1.4(1.1)$ & $1.6(1.2)$
\end{tabular}

Conclusion: Physicians reported decreasing satisfaction with treatment for their OA patients as disease severity increased, despite increasing use of opioids and numbers of classes of prescribed drugs.

Disclosure of Interests: Philip G Conaghan Consultant of: AbbVie, BMS, Eli Lilly, EMD Serono, Flexion Therapeutics, Galapagos, GSK, Novartis, Pfizer, Speakers bureau: AbbVie, Eli Lilly, Novartis, Pfizer, Lucy Abraham Shareholder of: Pfizer, Employee of: Pfizer, Peita Graham-Clarke Shareholder of: Eli Lilly and Co, Employee of: Eli Lilly and Co, Lars Viktrup Shareholder of: Eli Lilly and Company, Employee of: Eli Lilly and Company, Joseph C Cappelleri Shareholder of: Pfizer Inc, Employee of: Pfizer Inc, Craig Beck Shareholder of: Pfizer, Employee of: Pfizer, Andrew G Bushmakin Shareholder of: Pfizer Inc, Employee of: Pfizer Inc, Niall Hatchell: None declared, Emily Clayton: None declared, James Jackson: None declared

DOI: 10.1136/annrheumdis-2020-eular.4776

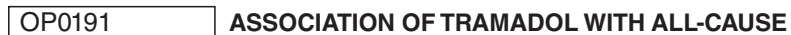 MORTALITY, CARDIOVASCULAR DISEASE, VENOUS THROMBOEMBOLISM AND HIP FRACTURES AMONG PATIENTS WITH OSTEOARTHRITIS. A POPULATION- BASED STUDY}

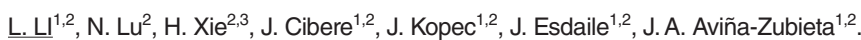
${ }^{1}$ The University of British Columbia, Vancouver, Canada; ${ }^{2}$ Arthritis Research Canada, Richmond, Canada; ${ }^{3}$ Simon Fraser University, Burnaby, Canada

Background: Both tramadol (narcotic-like drug) and nonsteroidal anti-inflammatory drugs (NSAIDs) are prescribed for pain relief among osteoarthritis (OA) patients. Evidence comparing risks of adverse events between tramadol and NSAIDs users is inconclusive.

Objectives: To examine the association of tramadol with all-cause mortality, cardiovascular disease (CVD), venous thromboembolism (VTE) and hip fractures ( $\mathrm{HFx}$ ) compared with NSAIDs and codeine in OA.

Methods: Design: Sequential propensity score-matched cohort study. Sample: All patients with OA who received medical care from 2005 to 2014 in the entire province of British Columbia, Canada. Tramadol cohort: Initial prescription of tramadol $(n=56325)$. Four comparator cohorts: the initiation of one of the following: naproxen $(n=13798)$, diclofenac $(n=17675)$, cyclooxygenase-2 [Cox-2] inhibitor $(n=17039)$, or codeine (a weak opioid) $(n=7813)$. Patients required to be prescribed neither tramadol nor its comparators during the year before the initial prescription date (i.e., index date). Outcomes: 1) all-cause mortality; first ever 2) CVD, 3) VTE, 4) HFx within the $1^{\text {st }}$ year after the initiation of tramadol or its comparators. Follow-up: from index date until the event occurred, disenrollment, or the end of a 1-year follow-up period. Statistical analysis: We created baseline covariates (demographics, comorbidities, medications and health resource utilization) from the year prior to the index date. Calendar years from 2005 to 2014 were divided into 10 blocks; propensity scores were calculated using logistic regression within each block. We used 1:1 greedy matching method. We estimated hazard ratios (HRs) using Cox proportional hazard models.

Results: After propensity score matching, 112650 patients with OA were included (mean age of 68 years, $62.8 \%$ were females). During the 1-year follow-up 296 deaths (21.5/1000 person-years) occurred in the tramadol cohort and 246 (17.8/1000 person-years) in the naproxen cohort (Table 1). All-cause mortality was higher for tramadol compared with all NSAIDs cohorts, but not with the codeine cohort (Table 1, Figure 1). Tramadol initiators have also a higher risk of CVD and VTE compared with the diclofenac and Cox-2 inhibitor initiators with HRs ranging from 1.2 to 1.7. Furthermore, tramadol was also associated with a higher risk of HFx compared with all NSAIDs cohorts (HRs ranging from 1.4 to 1.5). No significant difference was found between tramadol and codeine (Table 1).

Conclusion: OA patients initiating tramadol have an increased risk of mortality, CVD, VTE, and HFx within 1 year compared with NSAIDs, but no statistically significant difference in the risk was observed between tramadol and codeine. 